\title{
Brian Druker and Charles Sawyers receive the 2011 ASCl/Stanley J. Korsmeyer Award
}

hronic myelogenous leukemia (CML) was the first cancer to be linked to a clearly defined genetic defect, a chromosomal translocation that generates a constitutively active tyrosine kinase. In the 1990s, Brian Druker and Charles Sawyers (Figure 1) collaborated to develop the targeted therapies that transformed CML from a fatal disease to one that boasts a $90 \%$ cure rate. Their work has been widely recognized as revolutionizing the molecular treatment of cancer, and in April their contributions will be further celebrated as they receive the 2011 ASCI/Stanley J. Korsmeyer award. The JCI recently spoke to Druker and Sawyers about their research careers and this latest award.

JCI: How did you decide to do cancer research?

Druker: My interest in cancer research began in medical school, when we learned about the cure of childhood leukemias. I was fascinated by the fact that science had transformed a routinely fatal disease to one that was curable, but still required two years of highly toxic treatment. I just thought there had to be a better way, and I thought that the better way might actually occur during my lifetime, and I wanted to be a part of it.

Sawyers: I was struck by the notion that there were genes that cause cancer and excited by the idea that the scientific underpinnings of the disease seemed within reach. Also, when I rotated on the leukemia service, I saw patients who were almost my age getting these extremely powerful drugs that brought them to the brink of death, but then they'd recover and go into remission. It was an extremely moving experience, and it just gelled with the science that fascinated me - I knew that it was what I wanted to do.

JCI: What was the greatest obstacle you faced in getting imatinib (Gleevec) to cancer patients?

Druker: Well, unfortunately, there was more than just one. There was an enormous amount of skepticism in the scientific community about targeting kinases, partly because there was a view that one single target would be unlikely to be of value, because cancers are so complicated, and also because people thought that kinase inhibitors were likely to be toxic, because knockout animals of individual kinases are often embryonically lethal. From the drug companies' point of view, we were dealing with a rare disease and thus a very small market, so a drug company was looking at investing anywhere from $\$ 500$ million to $\$ 1$ billion in developing a drug, and the return on that investment just was not worth it. We turned that around by doing the preclinical scientific work to show that we could kill cancer cells without harming normal cells and also by giving the pharmaceutical industry a choice: they could develop the drugs or let us do it by licensing out the technology.



Figure 1

Brian Druker (left) and Charles Sawyers (right).

I think that carried the day for them and helped it go from an adversarial relationship to a partnership.

Sawyers: Another challenge was that in the midst of seeing Gleevec working so well, we also saw that patients in the advanced stages of the disease would relapse as quickly as they would respond, developing drug-resistant leukemia just a month or two later. What we discovered was that

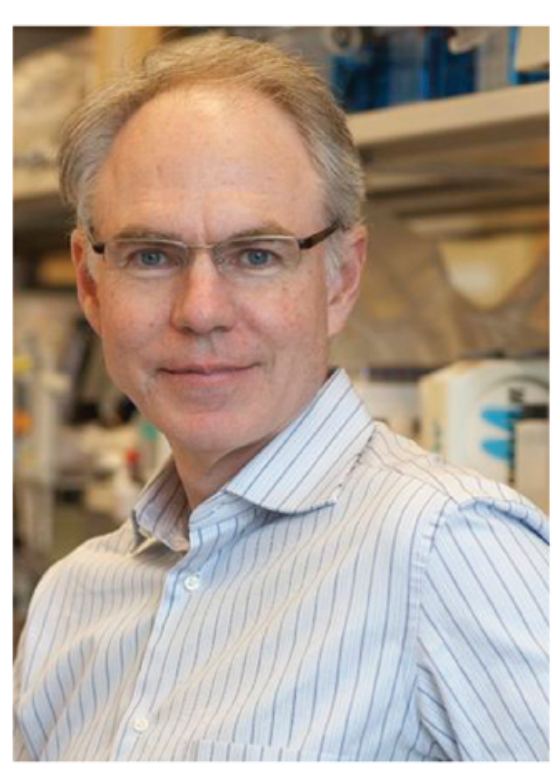

the patients who stopped responding had a new mutation that stopped the Gleevec from inhibiting the ABL protein the way it was supposed to. So we worked to find an inhibitor that wouldn't care about those mutations. . I didn't think of it as developing the second generation of inhibitors, just as shutting off this escape route that cancer cells were taking.

JCI: You developed imatinib specifically to treat CML patients. How widely useful do you think it and other kinase inhibitors can be in the fight against cancer?

Sawyers: They already are useful and continue to broaden in terms of their utility. There are approved drugs for 8 or 
JCI: What is capturing your attention in the laboratory most right now?

Sawyers: I am working on prostate cancer. Working on CML was an unbelievable, transforming experience for me, because I learned that when you understand the molecular driver of a cancer you can really help patients: drugs based on that principle actually worked. I decided that if we can get that principle to work for leukemia, we need to get it to work for solid tumors. I picked prostate cancer because there are drugs that work in late-stage prostate cancer, but resistance is the rule, rather than the exception. I had learned a set of guiding principles about how to tackle resistance and had come up with ways to treat it, and I applied that thinking to prostate cancer. As a result of that, we have a drug that came out of the work in my laboratory that is now in a phase III clinical trial, which we hope will get approved one day soon. That's been extremely gratifying, because it was a similar set of thought processes about how to tackle a problem that yielded similar fruit.

Druker: We're really excited about some of the functional screens that we're doing. We're taking leukemia samples from patients that we see in our clinic and looking for any kinase vulnerability or susceptibility that they might have. We can do the entire tyrosine kinome in a screen to look to see if any one particular kinase might be a good target in an individual patient. What we see is that about one-third of our patients will be susceptible to an individual kinase knockdown. And we're now using that information to try to identify the mechanism of dependence on that kinase but also to try to use it for therapeutic benefit.

JCI: So it sounds like personalized medicine will be pretty important to future treatment strategies.

Druker: It's going to be extremely important. What we're impressed by is how little homogeneity we're seeing. As we collect more and more samples, we do see categories, but what we're not seeing is large numbers of kinases that would be able to be targeted in one specific disease. So, for example, in lung cancer, the EGF receptor is mutated in 3\%-5\% of patients and ALK is mutated in 3\%-5\%. It's not like CML for which $100 \%$ of the cancers are dependent on BCR-ABL. But if you target the subset of patients, you can see rapid and dramatic responses. It's just that it requires more and more personalization.
JCI: How important do you think academic-industry collaborations are in advancing this kind of research?

Druker: Incredibly. I think it's important for each of us to do what we do well but also try to find ways to work together to accelerate discovery. So what academics do well is target identification. What industry does well is drug development. And together, we can run clinical trials. If we can find ways to look at our targets that have been identified and validated and form partnerships to accelerate the process of drug development, we could significantly advance progress.

JCI: As physician-scientists you get a chance to see both sides: the basic science and the patients who benefit from that work. How much do the patients you see in the clinic know about your contributions to the basic science of cancer therapy?

Sawyers: Well I certainly don't tell them! But in general, I think cancer patients are often much more knowledgeable about their disease than you might think. They do their homework, and they find out. And when we were doing the clinical trials, obviously the patients knew that it was research, and they knew that I had a role in it. I still get cards and letters from some of those patients. The patients are really the most important part of translational research; I think the connection to them is one of the most gratifying things about being a physician-scientist.

Druker: One of my very early phase I patients, after Gleevec burst onto the media scene in 1999-2000, came back for a visit and said, "I've never had a famous doctor before!" I looked back at him and said, "I've never been a famous doctor before!" My point being that I'm still the same doctor, and let's focus on what we need to do for you.

JCI: You've both been members of the ASCI for more than a decade. What does receiving the Stanley J. Korsmeyer Award mean to you?

Sawyers: To be recognized by your peers is incredibly flattering. But the other thing is that it's named for Stan Korsmeyer, whom I knew. I met him when I was a fellow training to be a cancer scientist, and I remember vividly him approaching me at a poster session, taking an interest in my work, and asking a bunch of right-atthe-heart questions, and it wasn't even his field. His scientific accomplishments are legend, but what really impressed me was his personal style. Later, it was fun to get to join him as a colleague, and we did become friends. I've also gotten to know many people that he trained - I've recruited some of them to our program. You can see in them how he's imparted this quality of clarity of thought, work ethic, and drive. And that drive is not over ambition or competitiveness but genuine intellectual interest in solving a problem. It's a style - it may sound subtle, but it's clear that he imparted that style to the people he trained.

Druker: Likewise, the most important thing is receiving an award named for a friend of mine. I knew Stan quite well; we interacted frequently at meetings, and although we never actually collaborated, we talked a lot about science and developed a very strong friendship. Knowing that he ultimately succumbed to his own cancer and now receiving an award that is for development of a targeted cancer treatment means an enormous amount to me.

JCI: This is the first time that the award has been given to two investigators jointly. How do you feel about sharing?

Druker: I believe the ASCI is recognizing that when you look at translational research, there's a cycle. When I first started on this project, I thought that you work to understand the molecular pathogenesis of a disease, then develop a drug against that target, and then you get that into clinical trials. And that was essentially what my work did. What Charles did was recognize that some patients became resistant, and you had to go back and do something for them. So what you really need is a cycle of discovery based on science, leading to better and better therapy. I believe ASCI is recognizing this cycle of translational research - that it doesn't stop or start but always keeps moving.

Sawyers: It's fantastic to share it. I think a shared prize speaks to the fact that if you really want to do something that big, you need to work as a team. We've always called ourselves "physician-scientists," but the track record shows that we've been mostly scientists. I think the field has changed now, in that the translational moments that arise in your career can be acted on, whereas a decade ago it really didn't make sense to act on them. But you can't do these things all on your own, and a shared award might help people recognize that.

\section{Kathryn Claiborn}

